\title{
A wearable active antenna for global positioning system and satellite phone
}

\author{
Arnaut Dierck, Hendrik Rogier, Senior Member, IEEE, and Frederick Declercq
}

\begin{abstract}
A wearable multiband circularly polarized active antenna is presented for use in Global Positioning System and Iridium satellite phone applications. The square patch antenna is constructed using flexible foam and fabric substrates and conductors etched on thin copper-on-polyimide films. The feed substrate integrates a compact low-noise amplifier chip directly underneath the antenna patch. The antenna performance is studied under bending conditions and in the presence of a human body. The active antenna exhibits a gain higher than $25 \mathrm{dBi}$ and a $3 \mathrm{~dB}$ axial ratio bandwidth exceeding $183 \mathrm{MHz}$ in free-space conditions and is robust to bending and on-body placement.
\end{abstract}

Index Terms-Circularly polarized antenna, dual-band antenna, wearable active antenna, Global Positioning System, Iridium

\section{INTRODUCTION}

I $\mathrm{N}$ the recent years, interest in wearable electronics has boomed. By using suitable materials such as textiles and foams, the electronic systems can be unobtrusively integrated into clothing. These so-called smart textile systems can be deployed in a variety of fields, and have been shown to function desirably in garments ranging from sporting apparel to public service outfits [1]-[9]. A comfortable integration into clothing, however, causes some design challenges in order to guarantee optimal performance of the active circuits and antennas present in the wearable electronic systems. Textile/foam substrates introduce additional losses, and, while flexibility is necessary for conformal integration into clothing, it makes the antennas susceptible to bending, which might affect their performance. Also, proximity to the body and other electronic devices must be taken into account.

Key in these designs is to maintain a high wearability and, at the same time, to provide a highly reliable communications link. In this respect, miniaturization of the on-body electronic system is vital, on the one hand making the electronic circuitry and antennas less bulky and in the meanwhile improving wearability, and, on the other hand, combining functionalities of different circuits/antennas into more compact electronic units, reducing potential weak links between these devices. When looking at the antenna side of things, it is thus advisable to replace multiple antennas by a single, broad band radiator. Electronics required for the different functionalities serviced by this antenna can then also be centralized and reduced in size. From this point of view, we investigated the possibility of integrating Global Positioning System (GPS) and Iridium

A. Dierck, H. Rogier and F. Declercq are with the Department of Information Technology (INTEC), Ghent University, 9000 Ghent, Belgium (e-mail: arnaut.dierck@intec.ugent.be).

Manuscript received March 19, 2012; revised July 31, 2012. satellite phone capabilities into one active antenna. The active part of the antenna consists of a low-noise amplifier (LNA) chip amplifying the incoming signal. This enhances both GPS and Iridium signal reception.

Performance studies of wearable antennas under different adverse conditions were already reported. In [10], [11] the influence of antenna bending and crumpling is evaluated, which affects the antenna impedance bandwidth and causes shifts in resonance frequency. In [12], effects of moisture absorption by the textile substrate, depending on the relative humidity, were studied. Increased humidity raises the relative permittivity and loss tangent of the substrate, in this way changing the resonant frequency and bandwidth of the antenna. When placed on-body [13], [14], antenna radiation pattern distortion, resonant frequency shift and bandwidth changes are measured. Several circularly polarized wearable patch antennas [15] for GPS [16], [17] and GPS/Iridium [18] were reported in literature. These antennas are inset [15] or probe [16]-[18] fed and make use of asymmetries in the patch to excite circular polarization. This provides good matching and axial ratio characteristics, albeit in a limited frequency range. Due to the above-mentioned challenges present in wearable antenna design, resonance frequency and bandwidth can shift, resulting in reduced performance. Also, the probe feed presents a weakness when the antenna is exposed to stress from bending, stretching or compression, whereas the inset feed necessitates integration of additional (active) components on the radiating side of the antenna, making them vulnerable to interference. This can be circumvented by using a probe to connect the inset-fed antenna to components on the antenna backside, leading however to the aforementioned probe-fed related drawbacks. While the cited publications present antennas with sufficient bandwidth to cover both GPS L1 and Iridium bands, the nature of the techniques used to realize circular polarization leads to circular polarization in a small frequency range that is insufficient to cover both GPS and Iridium bands (e.g. [17]: $<35 \mathrm{MHz}$ centered around the GPS L1 frequency; [18]: 25 MHz centered around the Iridium frequency). By using a hybrid coupler, it is our aim to increase the bandwidth in which the antenna is circularly polarized. The $183 \mathrm{MHz}$ wide bandwidth in which the antenna in our contribution is circularly polarized with an $\mathrm{AR}<3 \mathrm{~dB}$ clearly demonstrates this feature. Moreover, the extra bandwidth provided by the hybrid coupler ensures robustness against fabrication tolerances. For example, in [16], the total impedance bandwidth is indeed large enough to cover both GPS and Iridium frequencies. However, due to fabrication tolerances and inaccuracies in the measured electromagnetic 
properties of the used materials, the fabricated antenna bandwidth differs from the simulated bandwidth, leading to an $\left|S_{11}\right|$ exceeding $-10 \mathrm{~dB}$ at the GPS frequency (and even worse under certain bending conditions).

In this contribution, we present a robust active wearable circularly polarized GPS antenna. We propose an aperture fed topology [1], [2], thereby eliminating probes through the antenna substrate and to increasing robustness and flexibility. Circular polarization is achieved by using a discrete hybrid coupler, which provides a wideband circular polarization to ensure satisfactory performance at GPS and Iridium frequencies under bending and on-body conditions. To ensure proper signal reception, an LNA chip is integrated onto the antenna feed plane, providing a high level of integration to increase overall on-body system compactness and ruggedness, while amplifying the received signal for further processing. In this paper, to the authors' knowledge for the first time in literature, we present an active wearable antenna that has a chip LNA and discrete hybrid coupler directly integrated onto the textile antenna. Moreover, this topology results in an impedance bandwidth of $340 \mathrm{MHz}$ and a $3 \mathrm{~dB}$ axial ratio bandwidth of $183 \mathrm{MHz}$, which is much wider than currently found in literature for wearable antennas. Thereby, the new antenna provides stable coverage of both GPS and Iridium bands, when deployed on body and when subjecting the antenna to different bending conditions. The single-band active wearable GPS antenna discussed in [1], [2], which bears some resemblance in terms of topology to the currently presented design, but which made use of discrete components to implement the LNA, only partly satisfied the specifications for the GPS band. In particular, the discrete element LNA did not fulfill the matching requirements at the GPS frequency $\left(\left|S_{11}\right|<-10 \mathrm{~dB}\right)$. Moreover, the many discrete components formed weak links in the design that easily break when bending the antenna and the large footprint of the active circuit reduced the breathability of the design. Therefore, it was replaced by a more compact circuit based on an LNA chip with only three additional discrete components. This topology was then optimized to provide appropriate and robust matching at the desired frequencies, even when bending the antenna and deploying it on the human body. In the following text, we will first discuss the active antenna topology and design in Section II. The design evaluation is outlined in Section III.

\section{Active Antenna Design And Topology}

\section{A. Active Antenna Design Specifications}

The active antenna is designed to meet the requirements to adequately receive GPS and Iridium signals. First, this necessitates an antenna able to cover the $2.046 \mathrm{MHz}$ wide GPS L1-band centered around $1.575 \mathrm{GHz}$ and the Iridium spectrum ranging from $1.616 \mathrm{GHz}$ to $1.6265 \mathrm{GHz}$ [19]. Second, this calls for an antenna with a right-handed circularly polarized radiation characteristic in the aforementioned frequency range. The circular polarization is quantified by means of the axial ratio, and a $3 \mathrm{~dB}$ upper limit is set as a circular polarization figure of merit. Moreover, the antenna should be planar and low-profile to facilitate integration into clothing. To account for bending and body influence on the antenna bandwidth, attention is paid to ensure proper functionality under these adverse conditions. To minimize the influence of the body on the antenna, a topology radiating away from the body is preferred.

\section{B. Active Antenna Topology}

To provide a low-profile planar antenna that can be easily integrated into clothing, a microstrip patch antenna topology is selected. This ensures radiation away from the body in a semi-hemisphere, allowing sufficient beam width for a good coverage. As depicted in Fig.1, the microstrip patch is aperture coupled to two perpendicular feed lines through rectangular slots in the ground plane. The ground plane effectively shields the antenna patch from the active circuitry, integrated on the feed plane, and from the human body. The feed lines are connected to a discrete quadrature hybrid coupler. The coupler that was used in the design is the Anaren XC1400P-03S [20]. This coupler provides a fixed 90 degree phase difference between the feedlines, exciting circular polarization. At the other end, this coupler is connected to an LNA chip and a $50 \Omega$ termination. To generate circular polarization, a hybrid coupler was preferred over other techniques, such as irregularities in the patch or feed geometry, to provide a broad band and robust circular polarization. This reduces the sensitivity of the antenna to fabrication tolerances and to frequency shifts caused by antenna bending. A discrete component was chosen instead of a microstrip realization to reduce the footprint size, leaving place for the LNA chip to be integrated under the antenna patch while also reducing the vulnerability of this component to influences of antenna bending. The antenna layout is symmetric about the plane perpendicular to the $x y$ plane forming a $+45^{\circ}$ angle with the $\mathrm{x}$-axis. For the fabrication, flexible materials were used to ensure the wearability of the design. The conducting surfaces were etched on a copper-on-polyimide (PI) film, in which a $9 \mu \mathrm{m}$ copper layer is laminated onto a $25 \mu \mathrm{m}$ polyimide sheet. The antenna substrate consists of a polyurethane foam layer (typically found in the shoulder pads of protective garments) with a thickness of $7.25 \mathrm{~mm}$. This height was chosen to guarantee wideband performance of the patch antenna while conserving a relatively simple feed structure in order to guarantee an easyto-fabricate, robust design. For the feed substrate, $400 \mu \mathrm{m}$ thick aramid fabric is used, a textile typically used as an outer layer in protective garments. This layer is kept thin to minimize radiation from the feed circuit. The different layers were glued together by means of thermally activated adhesive sheets. The electromagnetic properties of the substrates are listed in Table I. The listed height of $450 \mu \mathrm{m}$ of the LNA substrate includes the thickness of the polyimide film of the feed and ground plane. We fabricated two versions of the antenna, one passive, the other one active. The active antenna comprises a discrete Maxim MAX2659 LNA chip [21], which provides high gain and low noise figure in a small package that can be compactly integrated into the antenna. The layout of the chip LNA is depicted in Figure 2. This layout implements a simple capacitor-inductor input matching network, formed 


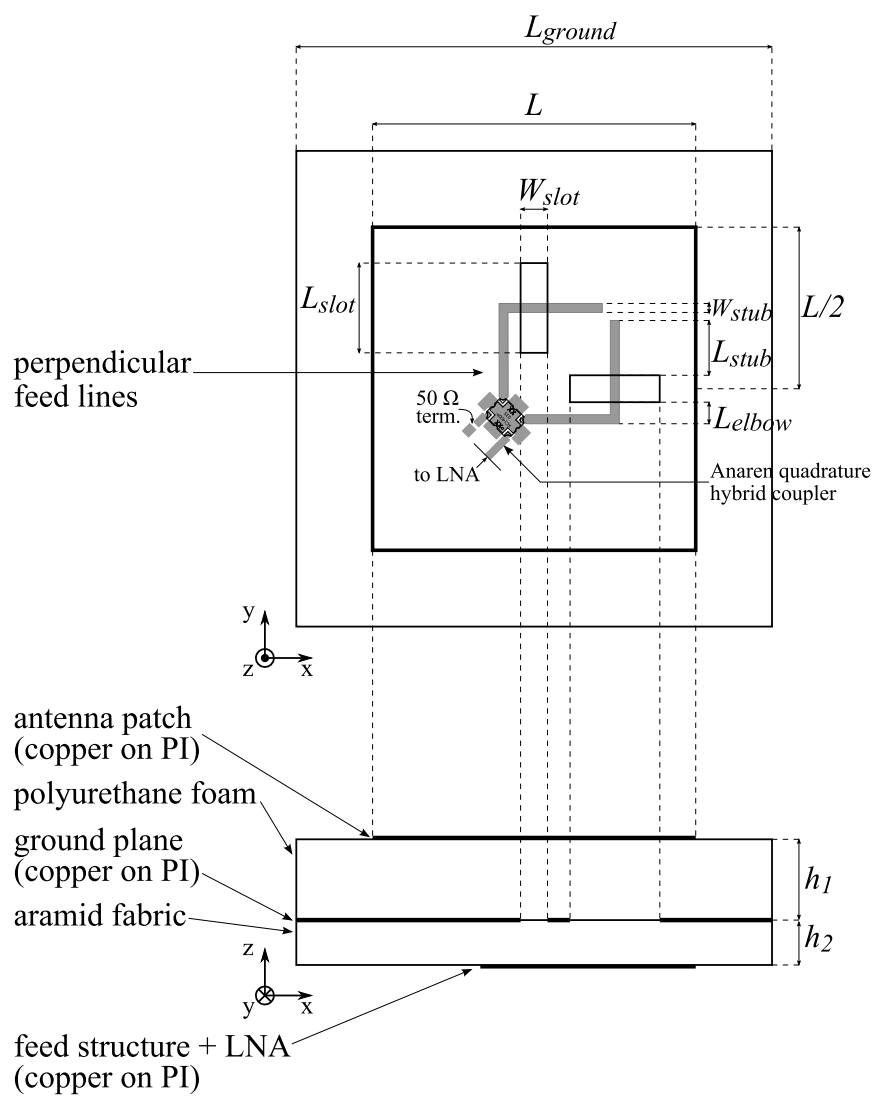

Fig. 1. Wearable GPS/Iridium active antenna topology

TABLE I

Electromagnetic Properties of the Active Antenna Materials

\begin{tabular}{cccc} 
& $\epsilon_{r}$ & TAN $\delta$ & MATERIALS \\
\hline $\begin{array}{c}\text { Antenna substrate } \\
h_{1}=7.25 \mathrm{~mm}\end{array}$ & 1.25 & 0.02 & polyurethane foam \\
\hline $\begin{array}{c}\text { LNA substrate } \\
h_{2}=450 \mu \mathrm{m}\end{array}$ & 1.775 & 0.02 & $\begin{array}{c}\text { aramid textile fabric } \\
\text { + polyimide layer }\end{array}$
\end{tabular}

by capacitor $C_{1}(470 \mathrm{pF})$ and inductor $L_{1}(6.8 \mathrm{nH})$, to connect to the $50 \Omega$ discrete hybrid coupler. The DC feed voltage is decoupled through capacitor $C_{2}(33 \mathrm{nF})$. The $50 \Omega$ microstrip lines (1.62 $\mathrm{mm}$ wide) in the layout are kept short to minimize losses. The LNA output is interfaced to the receiving equipment through a low-profile UFL-connector.

\section{Active Antenna Modeling}

An initial design based on the aforementioned antenna topology was modeled in ADS Momentum. This design was subsequently tuned and optimized from within the ADS schematic editor. Since the discrete hybrid coupler is a $50 \Omega$ matched component, the passive radiator and the LNA are designed to a $50 \Omega$ match. The optimized antenna dimensions are listed in Table II.

\section{Evaluation}

In this section, the measurement results are discussed and compared to the simulations. First, we elaborate on the LNA measurements. Second, we treat the antenna measurements.
TABLE II

ANTENNA DiMENSIONS

\begin{tabular}{cc} 
Parameter & Value $[\mathrm{mm}]$ \\
\hline$L$ & 70.85 \\
$L_{\text {ground }}$ & 100 \\
$L_{\text {slot }}$ & 30 \\
$W_{\text {slot }}$ & 5 \\
$L_{\text {stub }}$ & 18 \\
$W_{\text {stub }}$ & 1.62 \\
$L_{\text {elbow }}$ & 2.17
\end{tabular}

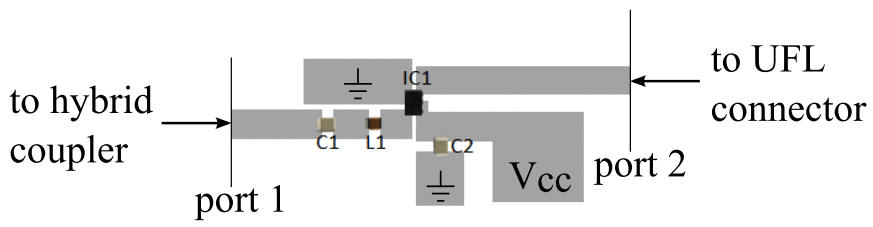

Fig. 2. Layout of LNA with chip amplifier

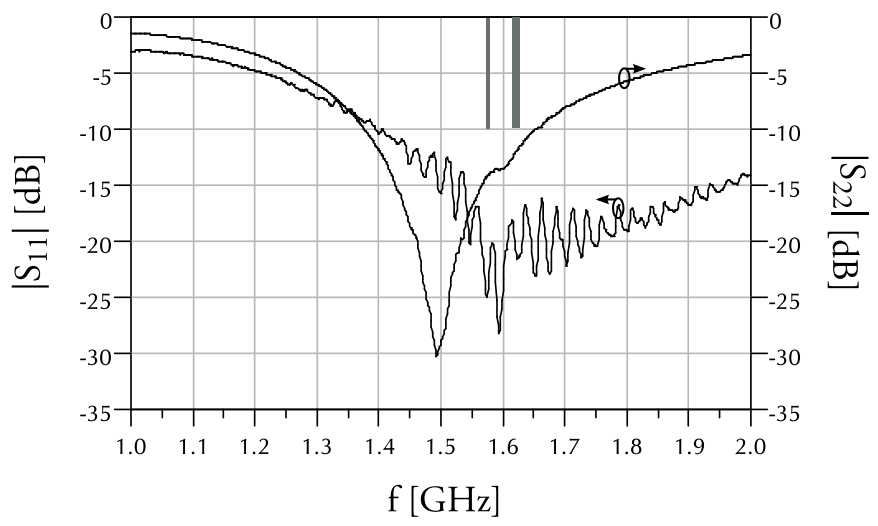

Fig. 3. Measured $\left|S_{11}\right|$ and $\left|S_{22}\right|$ of chip LNA

\section{A. LNA Evaluation}

Using the Agilent Technologies N5241A PNA-X Vector Network Analyzer, the scattering parameters and noise performance of the LNA were measured. These separate LNA measurements were carried out in order to validate the performance of the LNA circuit when implemented on a textile substrate. The noise measurement was performed using the source-corrected noise measurement technique embedded in the PNA-X system [22]. In Figure 3 the measured $\left|S_{11}\right|$ and $\left|S_{22}\right|$ of the LNA are depicted. We obtain a good in- and output match in the desired frequency range. In Fig. 4, the measured $\left|S_{21}\right|$ and $\left|S_{12}\right|$ are shown. A gain larger than $18 \mathrm{~dB}$ is observed in the GPS and Iridium frequency ranges. In Fig. 5, it is seen that the measured noise figure remains below $1.4 \mathrm{~dB}$ in the desired frequency range.

\section{B. Antenna Evaluation}

The passive and active antennas were measured in an anechoic chamber by means of the N5241A PNA-X VNA. A photograph of the complete active antenna prototype is depicted in Fig. 6. First, conventional free-space antenna measurements, without influence of bending or human proximity, were performed. Next, the antennas were also studied while subjected to bending in free-space and when integrated into 


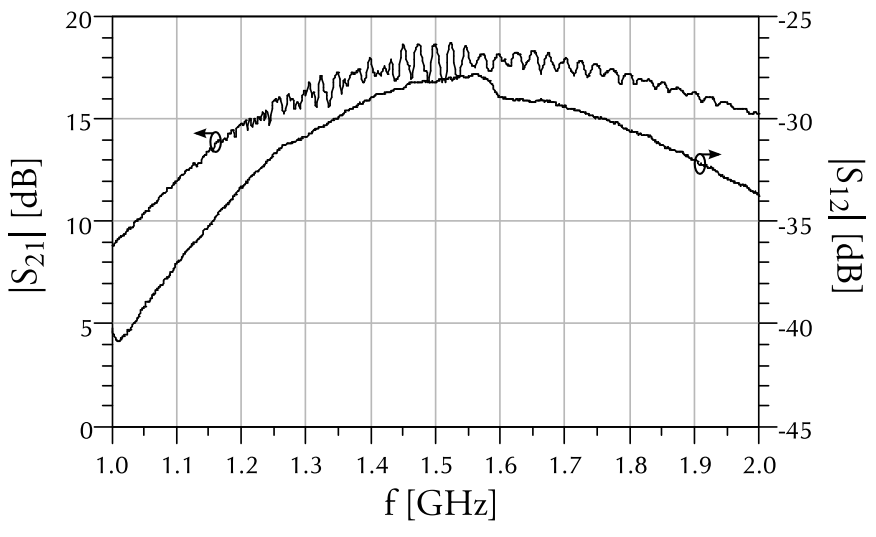

Fig. 4. Measured $\left|S_{21}\right|$ and $\left|S_{12}\right|$ of chip LNA

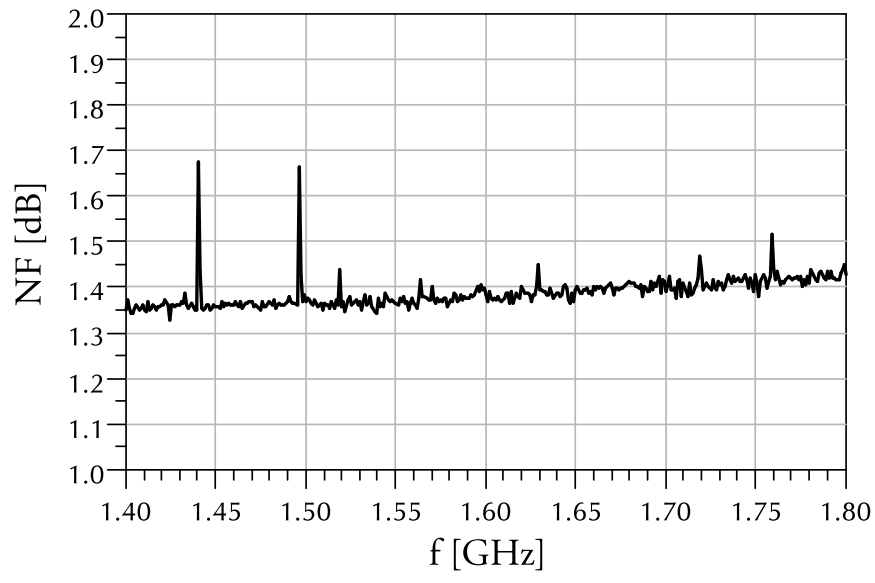

Fig. 5. Measured noise figure of chip LNA

a rescue worker jacket at different locations. To study the influence of free-space bending, both antennas were attached to a plastic cylinder with a $5 \mathrm{~cm}$ radius of curvature to emulate the geometry of a human arm. In this way, the antenna was bent in four directions according to the axes displayed in Fig. 1: along the $x$-axis, $y$-axis, and $y \pm 45^{\circ}$ axes. This is depicted in Fig. 7(a). For the on-body measurements, the antenna was placed in the rear section of a firefighter jacket and in the upper part of the sleeve, behind the outer shell fabric and the thermal and moisture barrier. In the rear section, the antenna was not subjected to any bending. In the sleeve, the antenna was subjected to bending along the upper arm, following the directions depicted in Fig. 7(a). The circumference of the upper arm is $20 \mathrm{~cm}$, corresponding to a radius of $3.2 \mathrm{~cm}$. The positions of the antenna integrated in the firefighter jacket are depicted in Fig. 7(b). This jacket was worn by a male of average height and weight. First, we treat the passive antenna, second the active antenna.

1) Passive Antenna Evaluation: The radiation pattern of the passive antenna in free-space is depicted in Fig. 8, together with the active antenna radiation pattern. The properties of the radiation pattern are listed in Table III. The measured $\left|S_{11}\right|$, as a function of frequency, is displayed in Fig. 9 for the passive antenna under free-space and on-body conditions, both in planar and bent state. The $\left|S_{11}\right|$ in free space is lower than $-10 \mathrm{~dB}$ from $1.512 \mathrm{GHz}$ to $1.7 \mathrm{GHz}$ and beyond. Data for

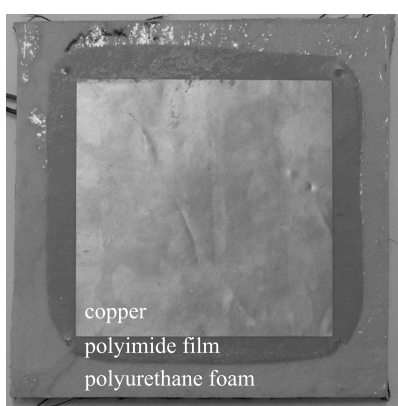

(a)

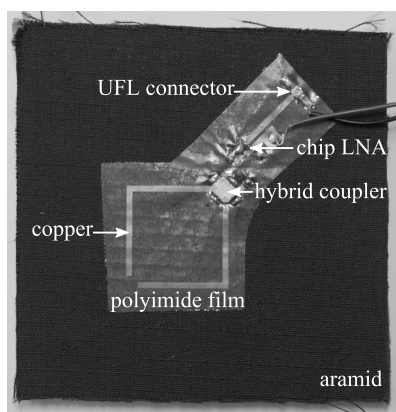

(b)
Fig. 6. Photograph of active antenna prototype top (a) and bottom (b)

TABLE III

AXIAL RATIO DATA OF THE DIFFERENT ANTENNAS MEASURED AT $1.6 \mathrm{GHz}$

\begin{tabular}{ccccc} 
ANTENnA & $\begin{array}{c}\text { GAIN } \\
{[\mathrm{dBi}]}\end{array}$ & $\begin{array}{c}3 \mathrm{DB} \\
\text { BEAM WIDTH }\end{array}$ & $\begin{array}{c}\text { AXIAL } \\
\text { RATIO [dB] }\end{array}$ & $\begin{array}{c}3 \mathrm{DB} \text { AR } \\
\text { BEAM WIDTH }\end{array}$ \\
\hline Passive & 5.2 & $66^{\circ}$ & 2.476 & $78^{\circ}$ \\
\hline $\begin{array}{c}\text { Active with } \\
\text { chip LNA }\end{array}$ & 25.1 & $68^{\circ}$ & 1.866 & $106^{\circ}$ \\
\hline
\end{tabular}

frequencies exceeding $1.7 \mathrm{GHz}$ were not measured during the radiation pattern measurements, since the standard gain horn that was used is not calibrated for measurements in this higher frequency range. A separate measurement of the antenna $\left|S_{11}\right|$ over a larger frequency range revealed matching up to 1.8 $\mathrm{GHz}$, resulting in an almost $300 \mathrm{MHz}$ matching bandwidth. Here, the influence of the discrete hybrid coupler, which is matched to $50 \Omega$, can clearly be seen. When subjecting the antenna to proximity of the body and to different bending conditions, the matching bandwidth does not significantly change. The hybrid coupler provides a robust, broad band $50 \Omega$ match. The measured antenna gain is depicted in Fig. 10. In free space, it reaches a maximum value of $5.5 \mathrm{dBi}$ at $1.619 \mathrm{GHz}$. It remains within $1 \mathrm{~dB}$ of the maximum value from 1.556 to $1.662 \mathrm{GHz}$, resulting in a $1 \mathrm{~dB}$ gain bandwidth of $106 \mathrm{MHz}$. In the different measurement scenarios, this $1 \mathrm{~dB}$ gain bandwidth is not significantly influenced, but maximum gain value and frequency are altered. The largest decrease in gain occurs when bending the antenna along the $y$-axis on the arm, resulting in a gain that is about $2.5 \mathrm{~dB}$ lower than in free-space conditions. The RHCP and LHCP gains are plotted in Fig. 11. We see that the RHCP gain is fairly insensitive to the different conditions imposed on the antenna. The LHCP gain, however, shows significant variations. In all scenarios, for GPS and Iridium frequencies, the RHCP gain remains at least $5.595 \mathrm{~dB}$ above the LHCP gain.

2) Active Antenna Evaluation: The free-space radiation pattern of the active antenna is depicted in Fig. 8. It exhibits a similar shape as the passive antenna radiation pattern, of course, providing a higher gain thanks to the integrated LNA. The active antenna forward gain is about $20 \mathrm{~dB}$ higher than the passive antenna forward gain. This is a little bit higher than what could be expected from the measured LNA gain of $18 \mathrm{~dB}$. Fabrication tolerances could, however, lead to slight variations between the standalone LNA and the LNA integrated into the 


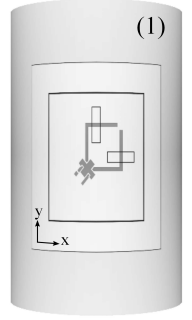

(3)
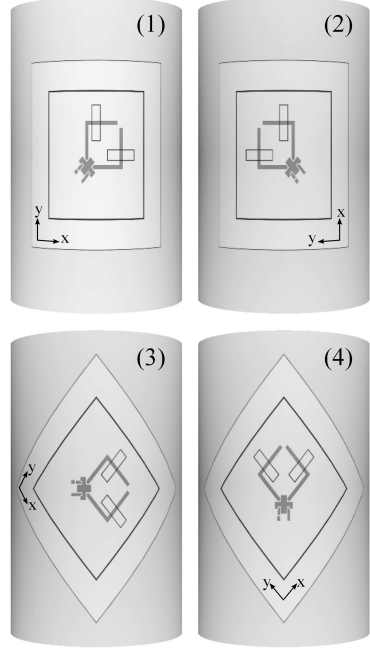

(a)

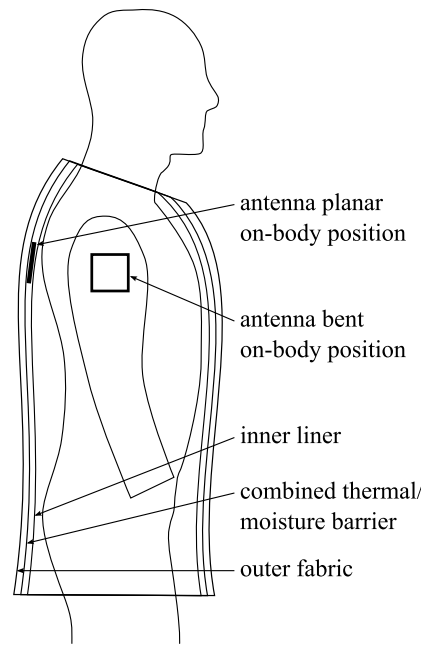

(b)
Fig. 7. (a): different bending directions of the antenna ((1) along the $x$-axis; (2) along the $y$-axis; (3) along the $y+45^{\circ}$-axis; (4) along the $y-45^{\circ}$-axis); (b): position of the antenna integrated in the firefighter jacket

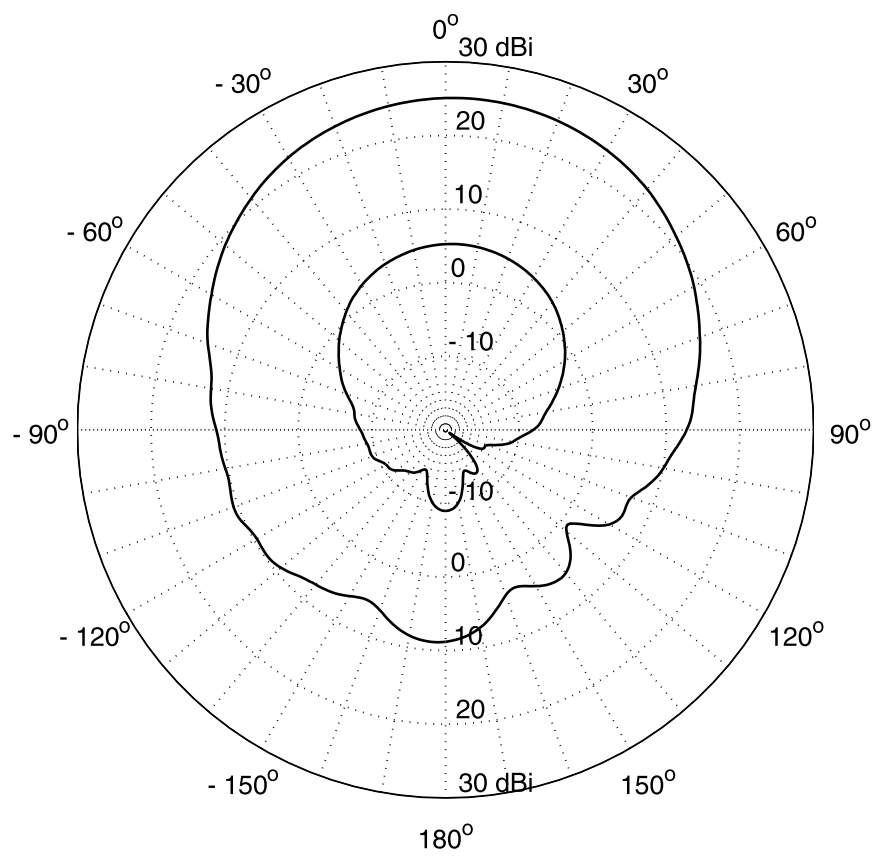

Fig. 8. Measured radiation pattern of passive and active antenna at $1.6 \mathrm{GHz}$ in the $x z$-plane

active antenna. The properties of the active antenna radiation pattern are listed in Table III. Although the antenna radiator topology is the same for the passive and active antenna, the axial ratio performance also slightly differs. The axial ratio is dependent on the alignment of the feed lines to the slots and the patch. The alignment of the prototypes is performed by hand, leading to variations. The measured $\left|S_{11}\right|$ is displayed in Fig. 12, as a function of frequency, for the active antenna under free-space and on-body conditions, both in planar and bent state. Compared to the passive antenna's $\left|S_{11}\right|$, the active antenna's $\left|S_{11}\right|$ exhibits a downward shift of the matching frequency. As the active antenna accommodates an LNA

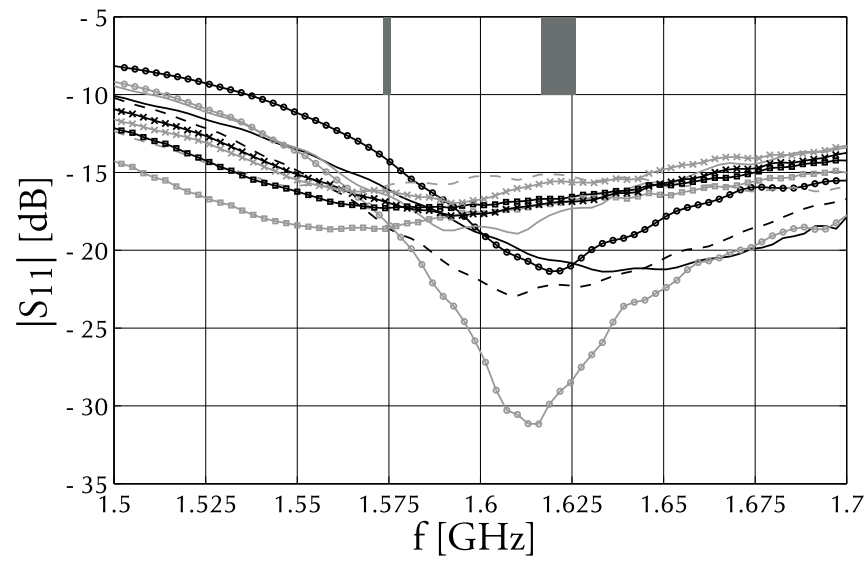

Fig. 9. Measured $\left|S_{11}\right|$ of passive antenna (- planar; - - on-body; $\odot$ bent $x$; — bent $y$; - - bent $y+45^{\circ} ;-\circ$ bent $y-45^{\circ}$; $\square-\operatorname{arm} x$ $\left.\square \operatorname{arm} y ; * \operatorname{arm} y+45^{\circ} ;-* \operatorname{arm} y-45^{\circ}\right)$

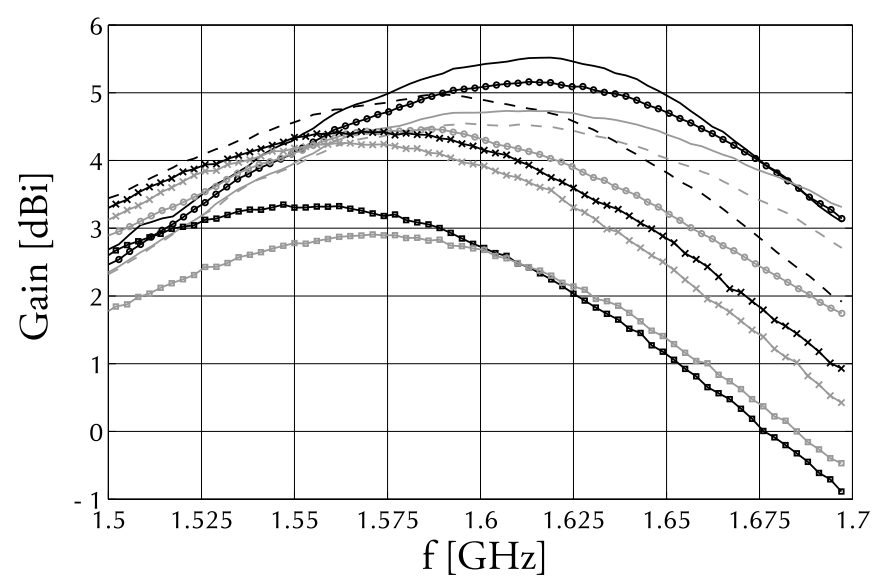

Fig. 10. Measured gain of passive antenna (- planar; - - on-body; $\rightarrow$ bent $x$; — bent $y$; - bent $y+45^{\circ} ; \multimap$ bent $y-45^{\circ} ; \square \operatorname{arm} x$ $\left.\leftarrow \operatorname{arm} y ; * \operatorname{arm} y+45^{\circ} ; * \operatorname{arm} y-45^{\circ}\right)$

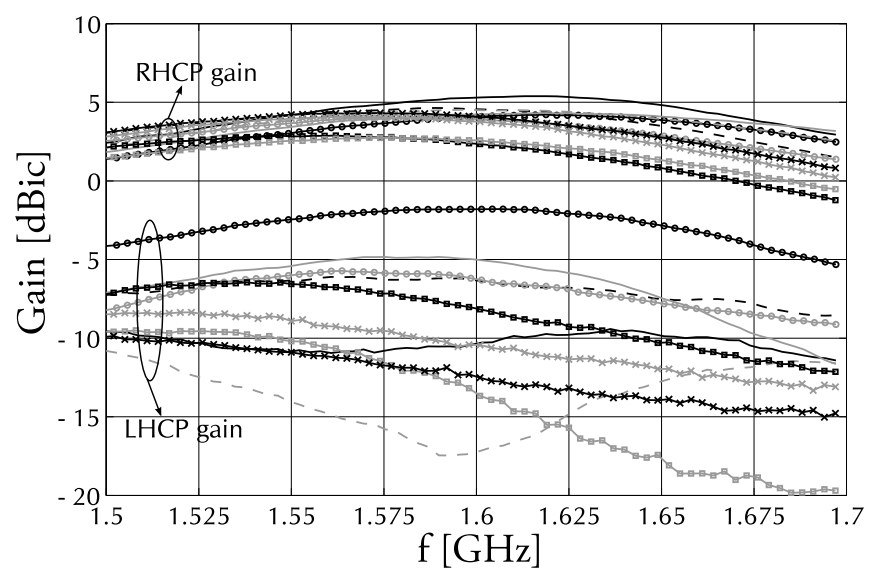

Fig. 11. Measured RHCP and LHCP gain of passive antenna (- planar; - - on-body; $\_$bent $x$; — bent $y$; - - bent $y+45^{\circ} ;-\_$bent $y-45^{\circ}$; $\left.\leftarrow \operatorname{arm} x ;-\operatorname{arm} y ; * \operatorname{arm} y+45^{\circ} ; * \operatorname{arm} y-45^{\circ}\right)$

chip with a matching network exhibiting a different $\left|S_{11}\right|$ characteristic than the hybrid coupler, this was to be expected. It must be noted that, under all circumstances, the $\left|S_{11}\right|$ of 
the active antenna remains lower than $-13 \mathrm{~dB}$ for the Iridium frequencies. However, it would be safer to move the center frequency of the matching upwards. This was not done in order to minimize the amount of additional discrete components. The $\left|S_{11}\right|$ is a characteristic of the matching network which is built into the chip LNA. Adding capacitors and/or coils can indeed change this characteristic, but would make the LNA layout more complex. The $\left|S_{11}\right|$ in free-space is lower than $-10 \mathrm{~dB}$ over the complete displayed frequency range. A separate measurement of the antenna revealed that the $\left|S_{11}\right|$ is lower than $-10 \mathrm{~dB}$ from $1.36 \mathrm{GHz}$ to $1.7 \mathrm{GHz}$, resulting in a matching bandwidth of $340 \mathrm{MHz}$. Subjecting the antenna to proximity of the body and to different bending conditions does not significantly change the matching bandwidth. The hybrid coupler and LNA provide a robust, broad band $50 \Omega$ match. The measured antenna gain is depicted in Fig. 13. In free-space, it reaches a maximum value of $25.43 \mathrm{dBi}$ at $1.625 \mathrm{GHz}$. It stays within $1 \mathrm{~dB}$ of the maximum value from 1.558 to $1.677 \mathrm{GHz}$, resulting in a $1 \mathrm{~dB}$ gain bandwidth of $119 \mathrm{MHz}$. This value is not significantly altered in the different measurement setups, however the maximum gain value and frequency change under influence of bending and on-body placement. The largest gain degradation occurs when bending the antenna on the arm along the $y$-axis. In Fig. 14, the measured RHCP and LHCP gain are depicted. Again, the RHCP gain is fairly insensitive to the different conditions imposed on the antenna, whereas the LHCP gain exhibits larger variations. For GPS and Iridium frequencies, the RHCP gain remains at least $10.44 \mathrm{~dB}$ higher than the LHCP gain. In Fig. 15, the measured axial ratio of the active antenna in free-space, on-body and bent positions is plotted as a function of frequency. For the free-space case, the axial ratio is lower than $3 \mathrm{~dB}$ for frequencies starting from $1.517 \mathrm{GHz}$ and extending beyond the measurement upper limit of $1.7 \mathrm{GHz}$, resulting in a $3 \mathrm{~dB}$ axial ratio bandwidth of over $183 \mathrm{MHz}$. When bent in free-space, the axial ratio exceeds $3 \mathrm{~dB}$ for most cases, though, with exception of the antenna bent along $y-45^{\circ}$, the axial ratio never exceeds $5 \mathrm{~dB}$ for the GPS and Iridium frequencies. It must be noted that this kind of bending represents a worst case scenario, which would only occur if the antenna was placed attached directly onto the human arm. When implemented in the lining of a jacket, the observed bending will be less severe. When placed on-body without bending, the axial ratio shifts downwards, resulting in a $3 \mathrm{~dB}$ axial ratio bandwidth larger than $200 \mathrm{MHz}$. When placed on a human arm, so that the antenna is subjected to both body presence and bending, the axial ratio stays below $3 \mathrm{~dB}$ for two out of the four bending directions. In terms of on-body axial ratio performance, it is optimal to place this antenna so that bending occurs along the $x$ or $y+45^{\circ}$-axis.

\section{CONCLUSION}

In this paper, we discussed the design of a combined GPS and Iridium active antenna. The antenna was constructed using flexible, wearable materials. Passive and active antennas were prototyped. The active receive antenna contains an LNA directly integrated on the antenna backside. Both antennas are

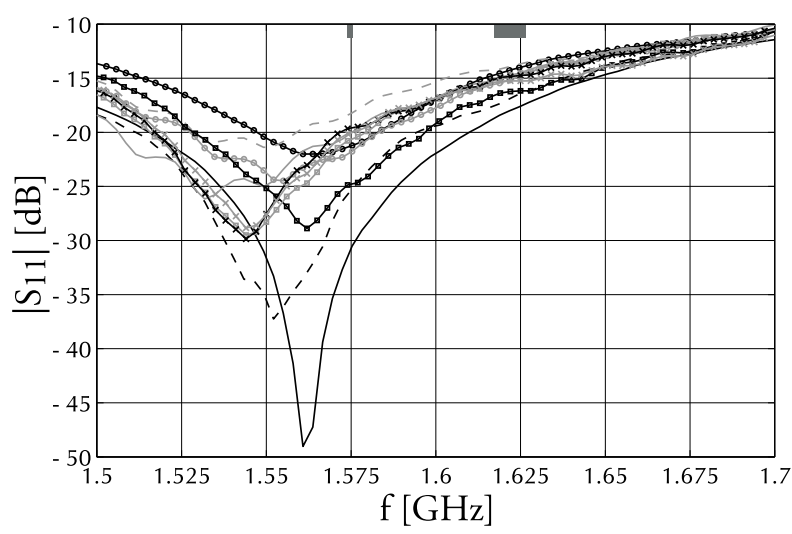

Fig. 12. Measured $\left|S_{11}\right|$ of active antenna (- planar; - - on-body; - - bent $x$; - bent $y$; - - bent $y+45^{\circ} ;-\circ$ bent $y-45^{\circ}$; $\square$ arm $x$; $\left.\square \operatorname{arm} y ;-* \operatorname{arm} y+45^{\circ} ;-* \operatorname{arm} y-45^{\circ}\right)$

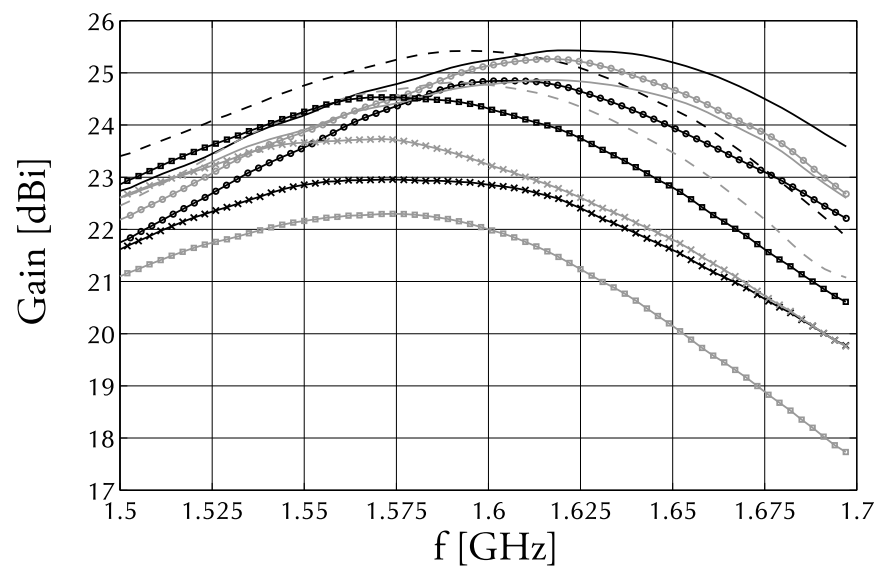

Fig. 13. Measured gain of active antenna ( - planar; - - on-body; $-\multimap$ bent $x$; — bent $y$; - - bent $y+45^{\circ} ;-\circ$ bent $y-45^{\circ} ; \square \operatorname{arm} x$; $\square \operatorname{arm} y$; $\left.\star \operatorname{arm} y+45^{\circ} ;-\operatorname{arm} y-45^{\circ}\right)$

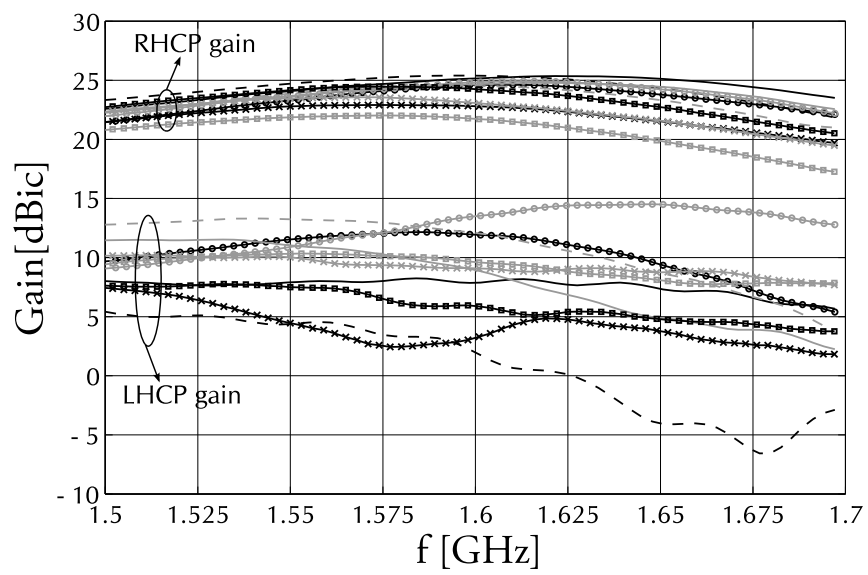

Fig. 14. Measured RHCP and LHCP gain of active antenna (- planar; - - on-body; $\_$bent $x$; — bent $y$; - - bent $y+45^{\circ}$; $-\circ$ bent $y-45^{\circ}$; $\left.\leftarrow \operatorname{arm} x ;-\operatorname{arm} y ; * \operatorname{arm} y+45^{\circ} ; * \operatorname{arm} y-45^{\circ}\right)$

robustly matched over a broad frequency range under bending and on-body conditions. The discrete hybrid coupler allows circular polarization over a wide frequency range. The active antenna realizes a gain larger than $25 \mathrm{dBi}$ in a $1 \mathrm{~dB}$ gain 


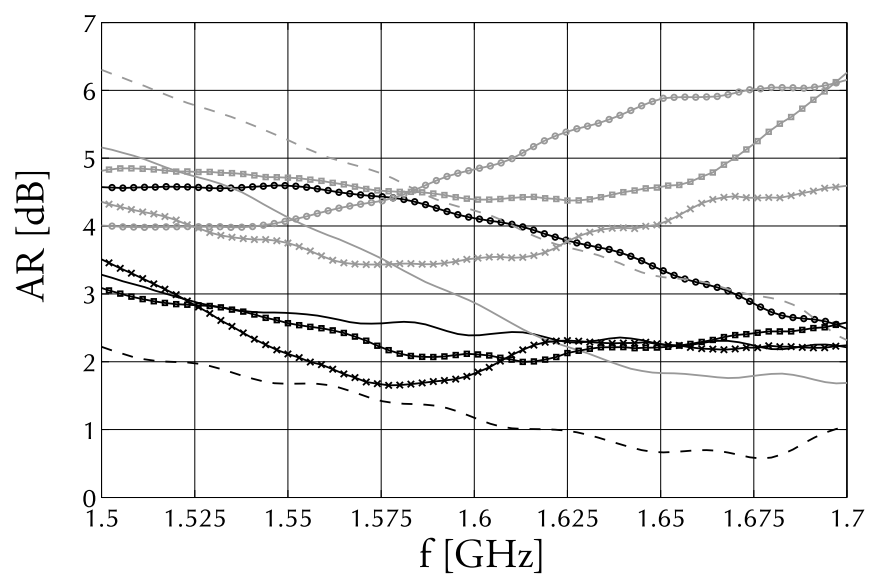

Fig. 15. Measured axial ratio of active antenna ( - planar; - - on-body; $\multimap$ bent $x$; — bent $y ;--$ bent $y+45^{\circ} ;-\odot$ bent $y-45^{\circ} ;-\square \operatorname{arm} x$; $\square \operatorname{arm} y ; * \operatorname{arm} y+45^{\circ} ; * \operatorname{arm} y-45^{\circ}$ )

bandwidth of $119 \mathrm{MHz}$. Circular polarization is ensured in a wide frequency range starting at $1.517 \mathrm{GHz}$ and extending beyond $1.7 \mathrm{GHz}$ in unbent state. When bent in free-space and on-body, the antenna's axial ratio remains lower than $5 \mathrm{~dB}$ for GPS and Iridium frequencies, except for the antenna bent along $y-45^{\circ}$, whose axial ratio exceeds $5 \mathrm{~dB}$ for Iridium frequencies. For the antenna placed on-body, the planar positions and the $x$ and $y+45^{\circ}$ bending positions result in an axial ratio which remains lower than $3 \mathrm{~dB}$. Each of these positions provides a sufficiently wide axial ratio bandwidth for proper GPS and Iridium reception. In the future, the possibility to coat the antenna with a breathable, water-resistant TPU coating [23] will be examined, increasing robustness by encapsulating the discrete components and solder joints, and at the same time providing an effective waterproof cover to withstand cleaning and washing. Moreover, the accuracy of the fabrication and alignment of the conductive structures will be augmented by using a laser powered cutting/alignment device, in this way providing a more consistent axial ratio performance in different prototypes.

\section{REFERENCES}

[1] A. Dierck, T. De Keulenaer, F. Declercq, and H. Rogier, "A Wearable Active GPS Antenna For Application In Smart Textiles," in 32nd ESA Antenna Workshop on Antennas for Space Applications, Ghent University, Belgium, 5-8 October 2010.

[2] A. Dierck, F. Declercq, and H. Rogier, "Review of active textile antenna co-design and optimization strategies," in RFID-Technologies and Applications (RFID-TA), 2011 IEEE International Conference on, sept. 2011, pp. $194-201$.

[3] G. Orecchini, L. Yang, M. Tentzeris, and L. Roselli, "'smart shoe": An autonomous inkjet-printed rfid system scavenging walking energy," in Antennas and Propagation (APSURSI), 2011 IEEE International Symposium on, july 2011, pp. $1417-1420$.

[4] B. Gupta, S. Sankaralingam, and S. Dhar, "Development of wearable and implantable antennas in the last decade: A review," in Microwave Symposium (MMS), 2010 Mediterranean, aug. 2010, pp. $251-267$.

[5] L. Vallozzi, W. Vandendriessche, H. Rogier, C. Hertleer, and M. L. Scarpello, "Wearable textile gps antenna for integration in protective garments," in Proceedings of the fourth European Conference on Antennas and Propagation. IEEE, 2010, p. 4. [Online]. Available: http://galayaa.com/EUCAP/data/1841658.pdf
[6] L. Vallozzi, P. Van Torre, C. Hertleer, H. Rogier, M. Moeneclaey, and J. Verhaevert, "Wireless communication for firefighters using dualpolarized textile antennas integrated in their garment," Antennas and Propagation, IEEE Transactions on, vol. 58, no. 4, pp. 1357-1368, 2010.

[7] L. Vallozzi, H. Rogier, and C. Hertleer, "Dual polarized textile patch antenna for integration into protective garments," Antennas and Wireless Propagation Letters, IEEE, vol. 7, pp. 440-443, 2008.

[8] A. Tronquo, H. Rogier, C. Hertleer, and L. Van Langenhove, "Robust planar textile antenna for wireless body LANs operating in $2.45 \mathrm{GHz}$ ISM band," Electronics Letters, vol. 42, no. 3, pp. 142-143, 2006.

[9] T. Kennedy, P. Fink, A. Chu, N. Champagne, G. Lin, and M. Khayat, "Body-worn E-Textile antennas: The good, the low-mass, and the conformal," Antennas and Propagation, IEEE Transactions on, vol. 57, no. 4, pp. 910-918, 2009

[10] Q. Bai and R. Langley, "Crumpling of PIFA Textile Antenna," Antennas and Propagation, IEEE Transactions on, vol. 60, no. 1, pp. 63 -70, jan. 2012.

[11] P. Salonen and Y. Rahmat-Samii, "Textile antennas: Effects of antenna bending on input matching and impedance bandwidth," Aerospace and Electronic Systems Magazine, IEEE, vol. 22, no. 3, pp. 10-14, 2007.

[12] C. Hertleer, A. Van Laere, H. Rogier, and L. Van Langenhove, "Influence of relative humidity on textile antenna performance," Textile Research Journal, vol. 80, no. 2, p. 177, 2010.

[13] C. Hertleer, A. Tronquo, H. Rogier, L. Vallozzi, and L. Van Langenhove, "Aperture-coupled patch antenna for integration into wearable textile systems," Antennas and Wireless Propagation Letters, IEEE, vol. 6, pp. 392-395, 2007.

[14] P. Salonen, Y. Rahmat-Samii, and M. Kivikoski, "Wearable antennas in the vicinity of human body," in Antennas and Propagation Society International Symposium, 2004. IEEE, vol. 1. IEEE, 2004, pp. 467470 .

[15] I. Locher, M. Klemm, T. Kirstein, and G. Troster, "Design and Characterization of Purely Textile Patch Antennas," Advanced Packaging, IEEE Transactions on, vol. 29, no. 4, pp. $777-788$, nov. 2006.

[16] P. Salonen, Y. Rahmat-Samii, M. Schaffrath, and M. Kivikoski, "Effect of textile materials on wearable antenna performance: a case study of GPS antennas," in Antennas and Propagation Society International Symposium, 2004. IEEE, vol. 1, june 2004, pp. 459 - 462 Vol.1.

[17] L. Vallozzi, W. Vandendriessche, H. Rogier, C. Hertleer, and M. Scarpello, "Design of a protective garment GPS antenna," Microwave and optical technology letters, vol. 51, no. 6, pp. 1504-1508, 2009.

[18] E. Kaivanto, M. Berg, E. Salonen, and P. de Maagt, "Wearable circularly polarized antenna for personal satellite communication and navigation," Antennas and Propagation, IEEE Transactions on, vol. 59, no. 12, pp. $4490-4496$, dec. 2011.

[19] S. Pratt, R. Raines, C. Fossa, and M. Temple, "An operational and performance overview of the iridium low earth orbit satellite system," Communications Surveys \& Tutorials, IEEE, vol. 2, no. 2, pp. 2-10, 1999.

[20] Anaren XC1400P-03S datasheet. [Online]. Available: http://www.anaren.com/Content/File/Product/XC1400P-03S Data Sheet Rev B.pdf

[21] Maxim MAX2659 Datasheet. [Online]. Available: http://datasheets.maxim-ic.com/en/ds/MAX2659.pdf

[22] K. Wong. Advancements in Noise Measurement. [Online]. Available: http://www.ewh.ieee.org/r6/scv/ims/archives/May2008Wong.pdf

[23] M. L. Scarpello, I. Kazani, C. Hertleer, H. Rogier, and D. Vande Ginste, "Stability and efficiency of screen-printed wearable and washable antennas," Antennas and Wireless Propagation Letters, IEEE, vol. 11, pp. $838-841,2012$.

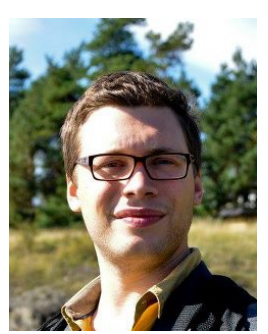

Arnaut Dierck was born in 1987. He received the M. Sc. Degree in electrical engineering from Ghent University, Ghent, Belgium in 2010.

Since September 2010 he has been working as a $\mathrm{Ph} . \mathrm{D}$. student at the electromagnetics group in the Department of Information Technology (INTEC) at Ghent University. His research activities concentrate on the design of active textile antennas for wearable applications. 


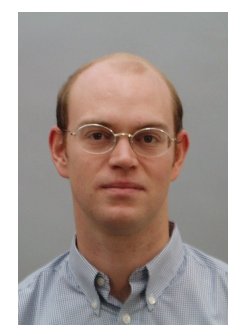

Hendrik Rogier was born in 1971. He received the Electrical Engineering and the Ph.D. degrees from Ghent University, Gent, Belgium, in 1994 and in 1999 , respectively.

He is currently a Full Professor with the Department of Information Technology. From October 2003 to April 2004, he was a Visiting Scientist at the Mobile Communications Group of Vienna University of Technology. He authored and coauthored about 80 papers in international journals and about 100 contributions in conference proceedings. $\mathrm{He}$ is serving as a member of the Editorial Boarding of IET Science, Measurement Technology and acts as the URSI Commission B representative for Belgium. His current research interests are the analysis of electromagnetic waveguides, electromagnetic simulation techniques applied to electromagnetic compatibility (EMC) and signal integrity (SI) problems, as well as to indoor propagation and antenna design, and in smart antenna systems for wireless networks.

Dr. Rogier was twice awarded the URSI Young Scientist Award, at the 2001 URSI Symposium on Electromagnetic Theory and at the 2002 URSI General Assembly. He is a Senior Member of the IEEE.

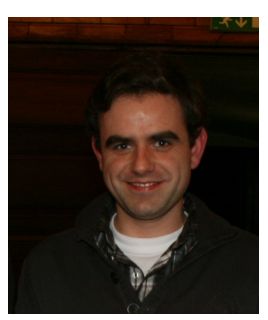

Frederick Declercq was born in 1983. He received the Master of Science degree in electronic engineering at Howest, university college West Flanders, Kortrijk, Belgium. He received the Ph.D. degree in electrical engineering at the faculty of engineering at Ghent University in 2011.

Since September 2005, he has been with the electromagnetics group, department of Information Technology (INTEC) at Ghent University. He is currently conducting his postdoctoral research at IMEC, Ghent University. His research interests are electromagnetic characterization of textile materials and flexible foam materials, the design of wearable active textile antennas and energy scavenging techniques for wireless sensor nodes applied in body area networks. 